\title{
Ethics in publishing
}

\author{
John M. Fitzpatrick, MD \\ Editor-in-Chief, BJU International, London, United Kingdom
}

See related article on page 177.

Cite as: Can Urol Assoc J 2012;6(3):181-2. htrp://dx.doi.org/10.5489/cuaj.12126

t was very interesting to read this paper on duplicate publications. It is just one of many transgressions which can potentially ruin someone's academic career. In this study, original articles published in the Journal of Urology in 2006 were reviewed and the incidence of redundancy was found to be gratifyingly low. ${ }^{1}$

In the rather pressurized world of academic urology it may be tempting to an individual to improve their curriculum vitae without adhering to the rigours of academic probity by, in effect, cheating in some way. It may seem like an easy option but if it is detected, the consequences for the individual will be very serious.

As an editor of an academic journal, I have, like all editors, to keep an eye out for duplication of publications, plagiarism, self-plagiarism and, the worst of all, scientific fraud. Regrettably, I have seen evidence of all of these during my time as editor.

Plagiarism is relatively uncommon, but does occur. On one occasion, I was sent a manuscript about a rather abstruse topic and on the advice of one of my Assistant Editors I sent it to two reviewers, neither of whom I know. One of them wrote back to say that he had several comments to make about the paper, not the least of which was that the author had "borrowed" rather a lot from a paper that he had written previously. In fact, when we applied the technology to verify this, it was clear that $75 \%$ of the manuscript overlapped the reviewer's previous paper. This episode of plagiarism had been discovered quite by chance and resulted in the author being reported to the Dean of his medical school and his being banned from publishing in the four main urological journals for an extended period of time.

Self-plagiarism is a very easy mistake to make, particularly by the younger and less-experienced. It is easy to think that one can cut and paste several paragraphs from previous papers that the author has written, and that this will not be noticed. It will. There are very effective software technologies which are now routinely applied to every manuscript that is submitted that if is relatively easy to discover when self-plagiarism has taken place. Sadly, the person who makes this mistake may once again be subjected to the rigours of the publishing laws. It's very important that everybody, and particularly young and inexperienced researchers who may not be fully aware that this is not permitted, realize the consequences of such a mistake.

Scientific fraud is awful, with frightful consequences not only for the perpetrator, but also for everyone else in the department, particularly the head of that department. It is in many ways like athletes taking drugs to enhance performance and having an unfair advantage over their competitors. It is relatively uncommon and, I feel confident when I say this, is likely to be discovered.

The article which has appeared in this issue of the CUAJ refers exclusively to "duplicate publications," but I have taken the liberty to widen the discussion to other time-consuming problems. One of the more perplexing aspects of duplicate publications is "salami-slicing," which the authors define in this manuscript as "portions of an index article repeated or continued." ${ }^{1}$ It is particularly difficult to decide the validity of publications which describe case-series (level of evidence 4 , by the way) of the first 500, then the first 1000, and so on. These series are repetitive of data and probably should not be sent out for review. The legality of "salami- slicing" is questionable and needs to be discussed further, as it may well be on the increase.

I apologize to CUAJ readers for ranting on about this. Receiving excellent submissions is one of the joys of editorship and this has given me great pleasure over the past 10 years as Editor-in-Chief of the BJU International. Unfortunately, on occasion, the trust implicit in this relationship is sometimes broken. As an editor, I have to make sure that the product is of the highest quality; the journal 
Fitzpatrick

must be educational, entertaining and free of any potential irregularities as described by Hennessey and colleagues. ${ }^{1}$ Increasingly, new technology is being developed which will prevent ethical breaches from taking place. We all must ensure that the highest academic standards are maintained and that the highest ethical standards are rigorously applied to what we publish.

Competing interests: None declared.

This paper has been peer-reviewed.

\section{Reference}

1. Hennessey KH, Williams AR, Afshar K, et al. Duplicate publications: A sample of redundancy in the Journal of Urology. Can Urol Assoc J 2012;6:177-80. http://dx.doi.org/10.5489/cuaj.11265

Correspondence: Professor John M. Fitzpatrick, Editor-in-Chief, BJU International, 10 Fitzroy Square, London W1T 5HP United Kingdom; fititzatrick@irishcancer.ie 